$\mathbb{T}$ periodica polytechnica

Civil Engineering

57/2 (2013) $113+122$

doi: $10.3311 / P P c i .7167$

http://periodicapolytechnica.org/ci

Creative Commons Attribution (1)

RESEARCH ARTICLE

\section{On the behaviour of concentrically braced frames subjected to seismic loading}

\author{
Dániel B. Merczel / Hugues Somja / Jean-Marie Aribert / János Lógó
}

Received 2012-10-31, revised 2012-12-10, accepted 2013-08-04

\begin{abstract}
This paper deals with the causes and the development of weak storey mechanisms in concentrically braced frames subjected to seismic action. In order to investigate this phenomenon, different braced frames were designed in accordance with Eurocode provisions. The design parameters and the obtained structures are presented in the paper. Later the results of a comprehensive nonlinear time history analysis carried out with various accelerograms are shown emphasizing the presence of weak storeys. The connection between the behaviour of the brace and the occurrence of the weak storey is investigated. It is described how the plastic deformation of the diagonals and the development of the weak storey are related. A theoretical influence of the brace deformation on the modal response of the braced frames is introduced and also proven by means of signal processing of the displacement time series of the numerical experiments. In the last chapter a possible redesign method is introduced to rule out the occurrence of weak stories.
\end{abstract}

\section{Keywords}

concentrically braced frames $\cdot$ earthquake $\cdot$ plasticity $\cdot$ weak storey mechanism

\section{Dániel B. Mercze}

Department of Structural Mechanics, Budapest University of Technology and Economics, Múegyetem rkp. 3, H-1111 Budapest, Hungary

Institut National des Sciences Appliquées de Rennes, Laboratory of Structural Mechanics, Avenue des Buttes de Coësmes 20, 35708 Rennes, France e-mail: Daniel-Balazs.Merczel@insa-rennes.fr

\section{Hugues Somja}

\section{Jean-Marie Aribert}

Institut National des Sciences Appliquées de Rennes, Laboratory of Structural Mechanics, Avenue des Buttes de Coësmes 20, 35708 Rennes, France

\section{János Lógó}

Department of Structural Mechanics, Budapest University of Technology and Economics, Múegyetem rkp. 3, H-1111 Budapest, Hungary

\section{Introduction}

Concentrically braced frames (hereinafter referred to as CBF-s) are frequently used as the vertical and lateral load bearing structure of multi-storey steel buildings, since the structure has numerous practical advantages in terms of implementation. The costly moment resisting joints and splices can be replaced by simple and cheaper semi rigid beam to column connections and also some cross sections can be smaller than of a moment resisting frame as the design value of the bending moment is strongly diminished and replaced by normal requisitions in the members of the braced bays.

Under seismic excitation, the large alternating horizontal inertia forces result in a plastic behaviour of the structure [10]. Classical design is made such that plastic deformations are expected to occur in the bracing bars only, as the braces are meant to carry all the lateral loads of the building [5,6]. Depending on the direction of the loading the bars in tension undergo plastic elongation and the ones in compression buckle. The global collapse mechanism is favourable because the total lateral displacement of the top is realized as the sum of all the drifts on every floor, therefore a considerable lateral drift can be achieved which is a main concern in seismic design. Furthermore the numerous members subjected to plastic deformation in repeated cycles absorb considerable energy through hysteresis loops of the stress - deformation diagram. This may contribute to some decrease of the storey drift at every floor in damage limit state and allows a major reduction of the design values of the accelerations in ultimate limit state. Although the global plastic yield mechanism is the one that simplified design procedures assume [13], it is well known and observed after recent earthquakes [11] that another collapse mechanism is more likely to develop [1,7]. The mechanism is often referred to as the weak storey mechanism, see Figure 1. The weak storey develops mainly because of the plasticity of the braces on one floor and on one floor only. When the braces reach the limit of their load bearing capacity, the columns have to carry all the excess horizontal inertia forces. While in the case of the global plastic mechanism the columns remain straight, a weak storey mechanism eventuates the double curvature of the columns as they counteract the horizontal 

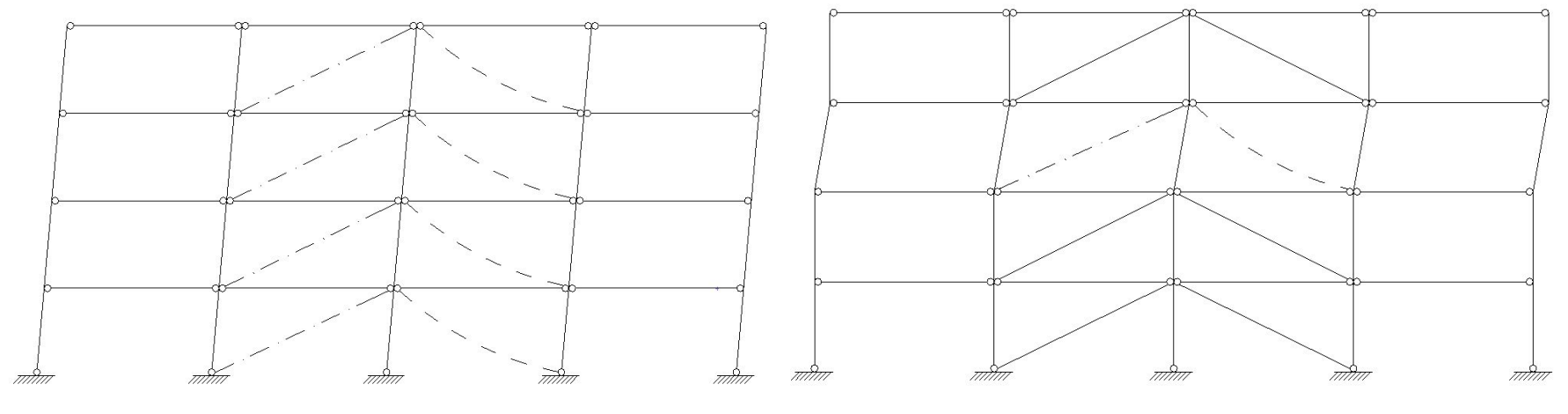

Fig. 1. Global and local plastic yield mechanisms of concentrically braced frames

forces by bending. If the lateral loading is adequately large plastic hinges form on the top and the bottom of the bent columns and a storey mechanism develops. In the case of this local mechanism the lateral displacement of the top is approximately equal to the storey drift of the weak storey only. Furthermore all the plastic dissipation of the building is realized only on one storey and the rest remain unexploited. As the mechanism develops through the plasticity of the columns, that are the main vertical load carrying members, the weak storey phenomenon facilitates the collapse of the weak floor and consequently the whole building. Therefore it is obvious that the development of the weak storey mechanism is to be prevented.

\section{Design and experimental seismic analysis of braced frames}

With the aim of better understanding the causes of the weak storey mechanism and to further analyze its development throughout an earthquake, a series of concentrically braced steel frame structures were designed. The design process was carried out with respect to the corresponding chapters of the Eurocode standards (EN-1991, EN-1993, EN-1998) and the designs were later verified with Nonlinear Time History Analysis (NTHA). The buildings for the experimental seismic analysis are identical in plan. The spacing of two adjacent columns is 6 metres in both directions. In the braced direction five columns form a four-bay frame, where the inner two are braced concentrically. In the perpendicular direction the frames are considered to be unbraced moment resisting frames, the columns are assumed to have continuous splices on every floor. However it is also assumed that in the perpendicular direction the adjacent frame is unbraced therefore one braced frame has to carry the horizontal inertia forces of two. The elevation of the buildings differs in terms of storey number. The number of floors are four, eight and twelve in the buildings denoted by CBF4, CBF8 and CBF12 respectively. The storey height is 3 metres on every floor in each building. In the perpendicular direction the five parallel frames are considered to be unbraced moment resisting frames. Consequently the columns are assumed to have continuous splices on every floor, however the base connection is considered as pinned. In the braced direction the beams are hinged at both ends as the lateral loads are carried by the braces. The contin- uous columns are positioned to have the larger flexural stiffness and load bearing capacity in the perpendicular direction, thus the columns act in the braced direction with their weak axis. The rectangular hollow section braces are concentric and hinged at both ends. The loading was assumed to be distributed between the steel members via concrete floor slabs. The dead load consists in a uniform loading of $6.77 \mathrm{kN} / \mathrm{m}^{2}$. The buildings were considered to have an office occupation where the imposed loading of the B category in EC1 gives $3 \mathrm{kN} / \mathrm{m}^{2}$ evenly distributed loading on the slabs. The $\psi_{2}$ combination factor was taken to be 0.3 therefore $30 \%$ of the live loading is concurrent with the seismic action. The earthquake acceleration response spectrum was considered to be the type one in EC8 assuming B type soil conditions. The design ground acceleration was taken to be $0.25 \mathrm{~g}$, where $\mathrm{g}$ is the acceleration of gravity. In the design the supposed behaviour factor ( $\mathrm{q}$ in EC8) was taken to be 4 in agreement with the structure-specific regulations of the standard. For the verification of the designed frames seven artificial accelerograms were used. The length of each excitation is 20 seconds and the spectra of the ground motions are fitted to the design spectrum. The NTHA was carried out for each accelerogram on different acceleration levels in order to examine the development of the weak storey effect as the seismic action rises. For this purpose the ground acceleration amplitude was multiplied by a constant ranging between 0.1 and 2.0. The different acceleration levels that the buildings were subjected to are: $0.10,0.25,0.50,0.75$, $1.00,1.25,1.50,2.00$. To obtain a more realistic and accurate design, wind loading was also taken into consideration in the calculation and the structural members were verified not only in seismic design situation, but in the ultimate limit state also. The wind effect was calculated with the assumption of terrain category 3 , however it did not make any change to the design. In the following table the applied cross-sectional sizes obtained by the standardized design are presented. The interior and the exterior columns were treated separately. Furthermore the relative slenderness $\bar{\lambda}$ and EC8 specified overstrength factor $(\Omega)$ results are also indicated. All these values are in accordance with EC8 $\left(1.3 \leq \bar{\lambda} \geq 2.0 ; \Omega_{\min } \leq 1.25 \Omega_{\max }\right)$.

For the NTHA a planar beam finite element model was used. As all the columns are continuous, the adjacent columns in the unbraced frame also contribute to the resistance in a plastic fail- 
Tab. 1. Sections of the members of the analysed braced frames

\begin{tabular}{|c|c|c|c|c|c|c|}
\hline Storey & Int. column & Ext. column & Beam & Brace & Slenderness & Overstrength \\
\hline 4 & HEA160 & HEA120 & IPE360 & SHS100×4 & 1.83 & 1.10 \\
\hline 3 & HEB180 & HEA160 & IPE360 & SHS100×6.3 & 1.87 & 1.18 \\
\hline 2 & HEB220 & HEA200 & IPE400 & SHS100×8 & 1.91 & 1.20 \\
\hline 1 & HEB260 & HEA220 & IPE400 & SHS $100 \times 10$ & 1.95 & 1.22 \\
\hline Storey & Int. column & Ext. column & Beam & Brace & Slenderness & Overstrength \\
\hline 8 & HEA160 & HEA120 & IPE360 & SHS $90 \times 4$ & 2.06 & 1.16 \\
\hline 7 & HEB180 & HEA160 & IPE360 & SHS $100 \times 5$ & 1.85 & 1.07 \\
\hline 6 & HEB220 & HEA200 & IPE400 & SHS100×6 & 1.87 & 1.13 \\
\hline 5 & HEB260 & HEA220 & IPE400 & SHS100×8 & 1.91 & 1.04 \\
\hline 4 & HEB280 & HEA240 & IPE400 & SHS100×8 & 1.91 & 1.15 \\
\hline 3 & HEB320 & HEA260 & IPN380 & SHS $100 \times 10$ & 1.95 & 1.04 \\
\hline 2 & HEM260 & HEA280 & IPN380 & SHS $100 \times 0$ & 1.95 & 1.08 \\
\hline 1 & HEM280 & HEA300 & IPN380 & SHS $120 \times 10$ & 1.60 & 1.12 \\
\hline Storey & Int. column & Ext. column & Beam & Brace & Slenderness & Overstrength \\
\hline 12 & HEA160 & HEA120 & IPE360 & SHS90×4 & 2.02 & 1.19 \\
\hline 11 & HEB180 & HEA160 & IPE360 & SHS90×6.3 & 2.06 & 1.10 \\
\hline 10 & HEB220 & HEA200 & IPE400 & SHS100×8 & 1.91 & 1.21 \\
\hline 9 & HEB260 & HEA220 & IPE400 & SHS120×8 & 1.57 & 1.21 \\
\hline 8 & HEB300 & HEA240 & IPN380 & SHS120×8 & 1.57 & 1.08 \\
\hline 7 & HEM240 & HEA260 & IPN380 & SHS $120 \times 10$ & 1.60 & 1.16 \\
\hline 6 & HEM280 & HEA280 & IPN380 & SHS120×10 & 1.60 & 1.08 \\
\hline 5 & HEM300 & HEA300 & IPN400 & SHS $120 \times 10$ & 1.60 & 1.02 \\
\hline 4 & HEM300 & HEB280 & IPN400 & SHS $140 \times 10$ & 1.35 & 1.13 \\
\hline 3 & HD320×300 & HEB280 & IPN400 & SHS $140 \times 10$ & 1.35 & 1.08 \\
\hline 2 & HD320×300 & HEB300 & IPN400 & SHS140×10 & 1.35 & 1.07 \\
\hline 1 & HD320×368 & HEB300 & IPN400 & SHS140×12.5 & 1.38 & 1.19 \\
\hline
\end{tabular}

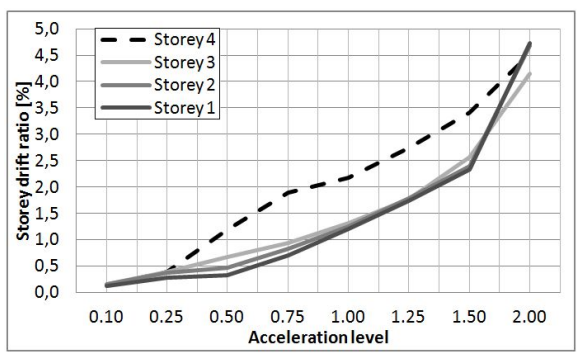

(a)

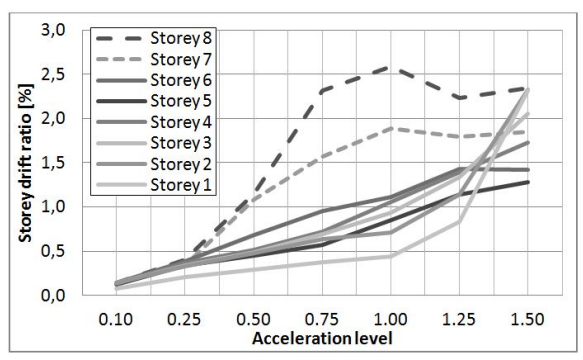

(b)

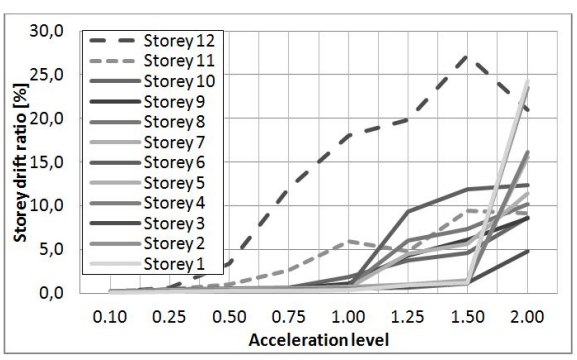

(c)

Fig. 2. (a) Relative storey drift results of the 4-storey braced frame (b) Relative storey drift results of the 8-storey braced frame (c) Relative storey drift results of the 12-storey braced frame 
ure mechanism such as the weak storey mechanism. Therefore these columns were added to the planar frame model and connected on every floor by contact elements. In order to obtain realistic energy dissipation in the elements that undergo plastic deformations the cyclic constitutive law of Giuffre - Menegotto - Pinto [17] with kinematic hardening was applied in the model. The material model provided force - displacement curves for the braces that are in good agreement with the results of experimental cyclic tests of rectangular hollow section braces. The calculations were carried out with the Newmark direct integration method. In the dynamic equation 5\% damping was taken into consideration via the two-parameter Rayleigh method, independently of the plastic dissipation. For the NTHA analysis the FinelG finite element software was used.

From the horizontal displacement results of the floor slabs the relative storey drifts of the subsequent floors were calculated. After looking up the maximum interstorey drift in all acceleration levels the averages of the seven results of the different ground motions were taken. In the diagrams of Figure 2 the averages of the maximum interstorey drift ratios are plotted against the acceleration levels, where the level 1.00 corresponds to the design level. The storey drift ratio is the interstorey drift of two adjacent floors divided by the storey height in percent.

In Figure 2 one can observe that the scatter of relative storey drifts occurs after the 0.25 acceleration level. This appears to be in agreement with the concept of the Eurocode according to which the design has been done to the elastic seismic action divided by four, which is the behaviour factor. In the four-storey CBF4 the interstorey drift on the fourth floor tendentiously exceeded the drift of the other floors. In CBF8 the upper two floors deviated from the manifold of the rest. On this diagram the level 2.00 is not shown as some floors reached unfeasibly large drift. In the diagram of CBF12 the obtained results are also very high, but only because the drift of the top floor deviates from the rest by a lot even for relatively small acceleration levels. In the same figure the $11^{\text {th }}$ floor also reaches high storey drift results compared to the floors below. Beyond the acceleration level 1.50 the tangent of the curves becomes steep for all buildings which can be interpreted as that the structures can not resist that magnitude earthquake. This is not surprising in any way as the designs were made for the level 1.00. On the top or on several upper floors the realized interstorey drift is significantly larger than on others storeys. The CBFs therefore can be considered to be susceptible to develop weak storey mechanisms, despite of that in the design the structure specific provisions of Eurocode were respected. Furthermore if we estimate the failure of the structures around 2-3 percent storey drift ratio based upon cyclic test result found in the available literature [12,16], we conclude that the buildings may collapse at lower acceleration level than 1.00 which is what they were designed for. For CBF8 the estimated collapse is around 0.75 acceleration level, while for CBF12 it is seemingly under 0.50 . In spite of the fact that the design of the braced frames was done with respect to the corresponding parts of the Eurocode, in the analysed buildings weak storeys develop and in two lead to early collapse.

\section{The behaviour of braces subjected to plastic defor- mations}

In the previous chapter we concluded that in the presented structures weak storeys developed in the top or upper floors. To further examine the underlying effects of the weak storey phenomenon we investigate the behaviour of the diagonals throughout the cyclic loading history. The axial force - axial deformation relation of a hollow steel brace with pinned ends subjected to cyclic loading is well described in the available literature [1,5]. In compression the slender braces buckle at a significantly lower axial force level than the plastic ultimate load bearing capacity, which is the limit of the resistance in tension. As the brace pairs lean against each other, their behaviour differs. With the relative horizontal displacement of two adjacent floor slabs the columns and beams of one braced bay form a parallelogram. While the brace parallel with the elongating diagonal is subjected to tension, the other is compressed. First the bar in compression, depicted in Figure 3 reaches its buckling resistance and as being pinned at both ends hypothetically it takes the form of a half sinus wave. The bent shape of the diagonal results in bending of the bar that is largest at the mid section, where the eccentricity $d$ of the normal force $F$ is the largest. As the interstorey drift increases further, the eccentricity and the bending moment grows until the combined effect of the normal force and the bending moment causes significant yield in the mid section of the brace which is amplified by the residual stresses in cyclic loading. Due to the formation of a semi plastic hinge early buckling occurs as a result of instability by limit resistance.

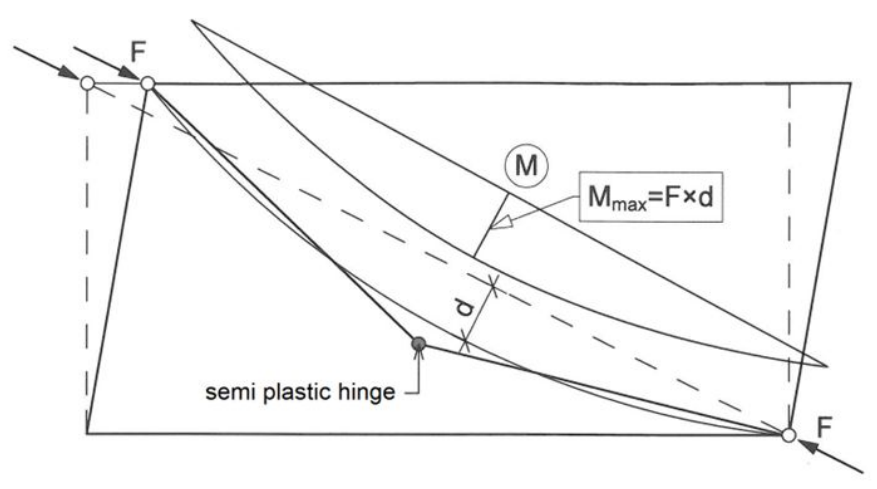

Fig. 3. Formation of plastic hinge and triangular deformation of diagonal

When the deformation of the tensile brace exceeds the elastic limit, plastic elongation is realized. In repeated load cycles the plastic strain of the bar cumulates. As the bar becomes longer, it has to be already in compression when the end nodes return to their initial position. Consequently a diagonal that has undergone preceding plastic tensile deformation is in compression or even buckled when the building is horizontally unloaded. The bidirectional cyclic loading causes plastic elongation and easier formation of a semi plastic hinge at the mid sections of both 


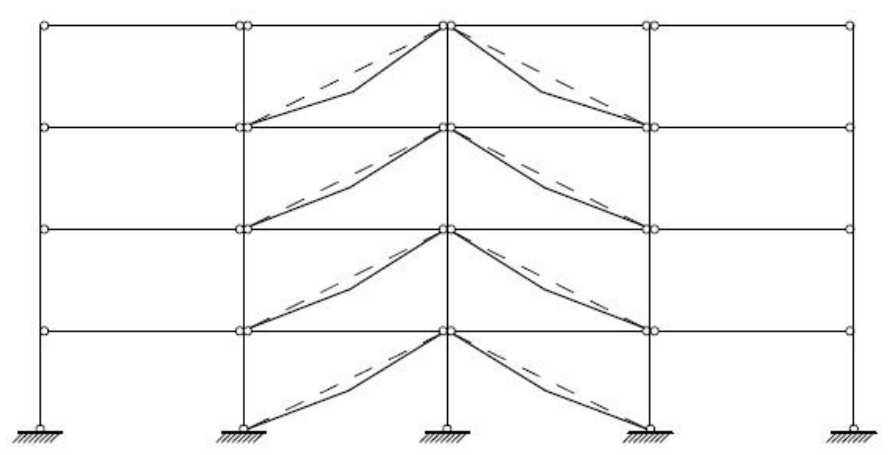

Fig. 4. Shape of four-storey braced frame after seismic action

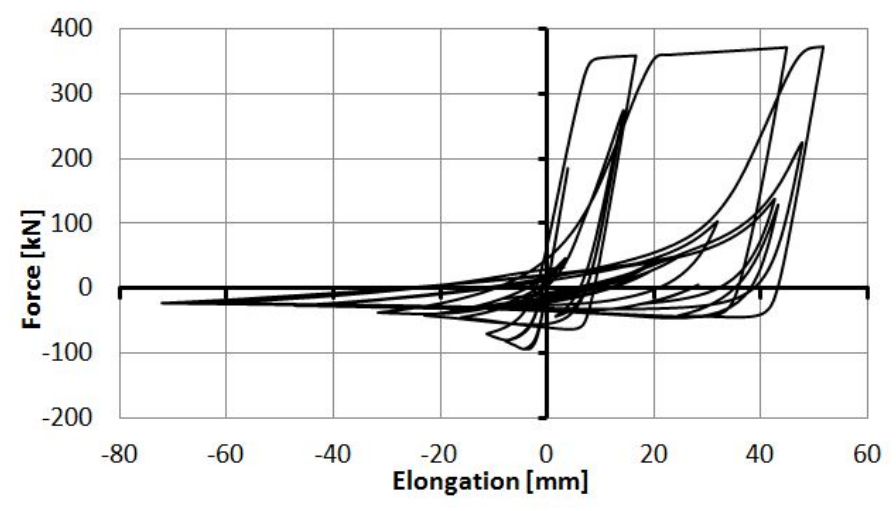

Fig. 5. Force - elongation diagram of diagonal on the top floor

diagonals of a storey. In Figure 4 the deformed shape of the four-storey braced frame is depicted after being exposed to a 20 second excitation. Furthermore, the axial force - axial elongation diagram of the left diagonal on the top floor during the same ground motion is presented in Figure 5 Both figures demonstrate the above described behaviour of the bracing members. In the diagram the subsequent plastic strains and the decrease of the axial force corresponding to the buckling of the brace can be observed. Upon the shape of the deformation of the braces we can conclude that the repeated cycles throughout the seismic event result in permanent triangular deformation of the braces. One can note that the magnitude of the triangular imperfection introduced to the system by the plastic strains may vary on the different floors. The larger triangular-like imperfection implies larger relative lateral drifts on the particular storey which indicates the formation of a weak storey. The weak storey yield mechanism is therefore related to large relative displacement of the adjacent floors, significant plastic elongation and rotation of the plastic hinge at the mid section of the braces. So the triangular imperfection of the braces, the growing interstorey drift and the formation of a weak storey are closely interrelated.

With the growth of the imperfection of the diagonals the rotation and the repeated alternating plastic deformation at mid section increases, causes cracks to appear and eventually leads to the breaking of the bar [12]. With the loss of the braces the bending moment from the horizontal inertia forces and the eccentric vertical forces causes failure in the columns of the weak storey and the building collapses. However, if the interstorey drifts on all the floors are about equal, the columns remain straight and therefore the global plastic mechanism develops. So, for a favourable behaviour it is not necessarily the magnitude of the drift that is to be limited, but an equality condition for all the storey drifts is to be met. One can also conclude then that a weak storey in a CBF is not weak in terms of adequacy to the horizontal loading, but weak in comparison with all the other storeys. Therefore the weak storey effect is a consequence of the structural arrangement, the dimensions and cross sections and not only a load bearing capacity issue. In other words, a CBF might withstand a high magnitude earthquake without the development of the global plastic mechanism if the members have enough reserve, but even the global mechanism may not prevent collapse if the bars are undersized. Hence the analysis of the susceptibility to the development a weak storey can be made independently of the expected seismic action on the actual building site.

\section{The effect of brace deformation on the overall be- haviour}

\subsection{Modal analysis of imperfect models}

So far a connection between the weak storey mechanism and the increasing plastic deformation of the braces has been set in evidence. The question arises, how and to what extent does this brace imperfection affect the global behaviour of the building in a seismic event? It can be assumed that the irreversible deterioration of the braces that are the main horizontal load bearing elements results in a significant alteration of the dynamic behaviour of the structure. To verify this assumption a series of natural frequency analyses were conducted on the elastic model of the four-storey braced frame. The perfect model with two straight bracing bars was altered. At the midpoint of two braces on the same floor different magnitudes of imperfection were introduced. The midpoints of the diagonals were pulled perpendicularly to the bar by 10 centimetres at each step up to 50 centimetres. This resulted in triangular shape braces. The considered maximal alteration $(50 \mathrm{~cm})$ corresponds to a $2.76 \%$ relative storey drift ratio which is in the estimated interval of the expected brace failure (2-3\%). The triangular alteration of the diagonals was done at every floor separately to analyse the effect of developed weak storeys. Also the same imperfections were applied on every floor simultaneously which corresponds to the development of the global yield mechanism. Furthermore a calculation was run on the perfect model with one diagonal on every floor, neglecting the buckled bar in compression, accordingly to an alternative Eurocode provision. In the Table 2 below the natural frequency results for the more relevant first and second modes are listed. The rows of the table correspond to the different levels of the introduced imperfection while the columns differ in the storey of the imperfection. For the sake of comparison it is noted that the frequencies of the perfect model with two braces on every floor are $1.23 \mathrm{~Hz}$ for the first and $3.21 \mathrm{~Hz}$ for the 
second mode, while the analysis with only one bar yielded 0.84 $\mathrm{Hz}$ and $2.26 \mathrm{~Hz}$ respectively. One can see in the results of the table that with the concurrent deformation of all the braces the decrease of the frequencies in the two modes is roughly proportional. However this is not the case when the triangular modification is only done to the braces of one floor. Consequently it is not only the frequency of the modes that changes.

The introduced imperfection of the braces modifies the stiffness matrix of the structure. It decreases the stiffness values corresponding to the end nodes of the altered braces, nothing else. Hence the new stiffness matrix of the structure is not proportional to the original, while the mass matrix remains the same. Therefore the mode shapes have to change also. In Figure 6 the natural frequencies, the modal shapes, the modal mass participation (MMP) and the equivalent horizontal loads calculated with the design spectrum can be seen. These results are presented for the perfect four-storey building (Fig. 6/a) and two imperfect ones. The two shapes in the middle (Fig. 6/b) correspond to a concurrent $40 \mathrm{~cm}$ imperfection on every floor while for the shapes on the right (Fig. 6, c) the same imperfection was introduced only on the $3^{\text {rd }}$ level. The mode shapes of Figure 6/a and $\mathrm{b}$ are seemingly similar. The main difference between the two is the ratio of the horizontal forces in the two modes. With the growing imperfection and the softening of the braced frame the importance of the second mode increases. This is due to the shape of the design spectrum and the change of the natural frequencies. As the frequency of the first mode drops, the period rises and the acceleration corresponding to this mode gradually shifts to lower values whereas the period of the second mode remains at or close to the plateau of the Eurocode design spectrum (see also Figure 9.). Therefore at the analysis of the global yield mechanism of concentrically braced frames keen attention is to be paid to the effect of the second mode or even the higher ones if their participation factors imply that. The mode shapes of the building with a developed weak storey show that the first mode is approximately a rigid bodily movement of the floors above the weak one and the second is a linear-shape displacement of the floors below the weak storey. Also it can be seen that the upper modes are negligible as their mass participation is low.

The fundamental mode of the locally imperfect model on the right has a reduced mass participation in comparison with the other models and the equivalent horizontal forces calculated from it are prevailing above the weak storey. Consequently we tend to conclude that by the increase of the plastic deformation in the braces of one storey the stiffness of that particular floor decreases. This might yield to a rearrangement of the horizontal inertia forces in a way that this inflicts an increase in the storey shear on the floor already subjected to plastic strains. This increase of the storey shear results in a recurring cycle as it will lead to the realization of further and cumulating plastic deformation on the floor under consideration. Hence the development of the weak storey mechanism could be regarded as an auto exciting phenomenon under cyclic seismic action.

\subsection{Frequency analysis of the displacement results}

The theory of the deterioration of the diagonals and its effect on the behaviour under dynamic loading was elaborated with the modal analysis of braced frames with deformed diagonals. Though the concept of deforming the braces was based on the nonlinear time history analysis results of the different braced frames, in this chapter another link between these results and theory presented above will be set in evidence. If the permanent deterioration of the diagonals has the previously introduced effect on the modal frequencies it has to be reflected in some way in the NTHA results as well. Upon the analysis results of CBF4 we concluded that the weak storey phenomenon occurs on the top floor. Therefore we analyse the horizontal displacement results of this floor with appropriate signal processing tools. By Fourier transform we can convert the displacement series from the time domain to the frequency domain by integrating over the whole time axis. But as our aim is to investigate the change of the frequency components on the non-stationary signal we need to keep the time variable. Short-time frequency transformation however can give a better solution. Applying this transformation we calculate Fourier transforms over predefined time windows. The weakness of this procedure is that the fixed-width time window may not be adequately close to the frequency of the signal. It may be a lot larger perhaps and this yields a bad resolution in some intervals. Consequently the chosen and appropriate tool is wavelet transformation of the time series [14,15]. The main goal of the wavelet transformation is to decompose an arbitrary function into elementary contributions. The wavelet transform measures the similarity of the analysed signal function and a series of wavelets with different translation in time and resolution in the frequency domain. The wavelet transform of the signal $\mathrm{x}(\mathrm{t})$ by definition is the inner product in the Hilbert space of the function and a family of wavelets:

$$
W(a, b)=\frac{1}{\sqrt{a}} \int g^{*}\left(\frac{t-b}{a}\right) \cdot x(t) d t
$$

where $g^{*}(t)$ is the complex conjugate of the mother wavelet function which generates the family of the wavelets. The mother wavelet is dilated by parameter a and translated by b which vary continuously so that a series of son wavelets are created. The mother wavelet is assumed to lie in the $\mathrm{L}^{2}$ space of square Lebesque-integrable functions. Also it has to have compact supports and needs to satisfy the admissibility condition that essentially means that $\mathrm{g}(\mathrm{t})$ is of zero mean.

$$
\int g(t) d t=0
$$

One possible choice as the mother wavelet is the Morlet function which is a modified version of the Gabor wavelet.

$$
g(t)=\exp \left[\frac{-\beta^{2}(t-b)^{2}}{a^{2}}\right] \cdot \cos \frac{\pi(t-b)}{a}
$$

This complex expression defines a harmonic function that decays exponentially on both sides over a time interval around $\mathrm{t}=\mathrm{b}$. 
Tab. 2. Natural frequencies of models with triangularly deformed braces

\begin{tabular}{|c|c|c|c|c|c|c|c|c|c|c|}
\hline \multirow{3}{*}{$\begin{array}{l}\text { imperfection } \\
\text { magnitude } \\
\text { [cm] }\end{array}$} & \multicolumn{5}{|c|}{ Natural frequency of mode $1[\mathrm{~Hz}]$} & \multicolumn{5}{|c|}{ Natural frequency of mode $2[\mathrm{~Hz}]$} \\
\hline & \multicolumn{5}{|c|}{ storey of imperfection } & \multicolumn{5}{|c|}{ storey of imperfection } \\
\hline & 1 & 2 & 3 & 4 & all & 1 & 2 & 3 & 4 & all \\
\hline 10 & 0.95 & 0.99 & 1.03 & 1.11 & 0.69 & 2.75 & 3.12 & 2.95 & 2.36 & 1.90 \\
\hline 20 & 0.67 & 0.87 & 0.78 & 0.85 & 0.41 & 2.52 & 3.07 & 2.71 & 1.90 & 1.13 \\
\hline 30 & 0.54 & 0.76 & 0.65 & 0.67 & 0.29 & 2.46 & 3.03 & 2.62 & 1.79 & 0.82 \\
\hline 40 & 0.47 & 0.59 & 0.58 & 0.56 & 0.22 & 2.43 & 2.99 & 2.58 & 1.75 & 0.65 \\
\hline 50 & 0.43 & 0.57 & 0.54 & 0.50 & 0.18 & 2.42 & 2.98 & 2.56 & 1.73 & 0.56 \\
\hline
\end{tabular}

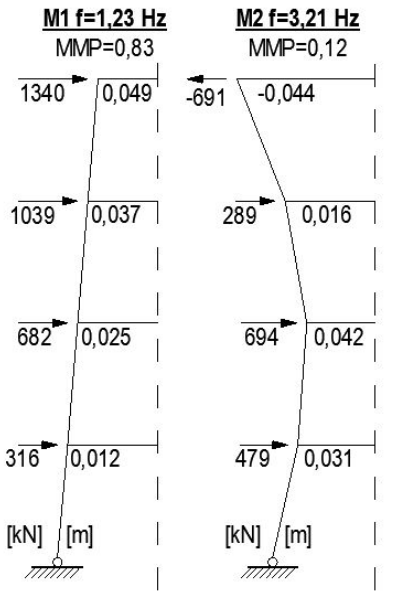

(a)

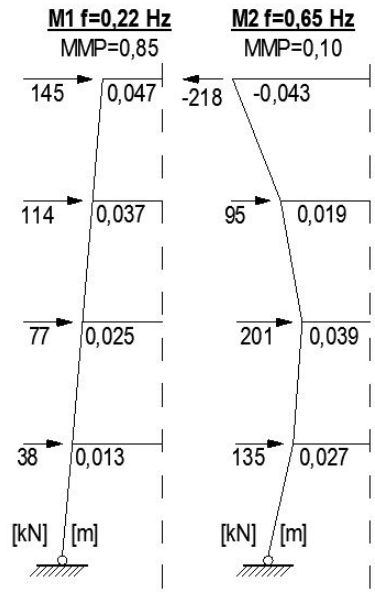

(b)

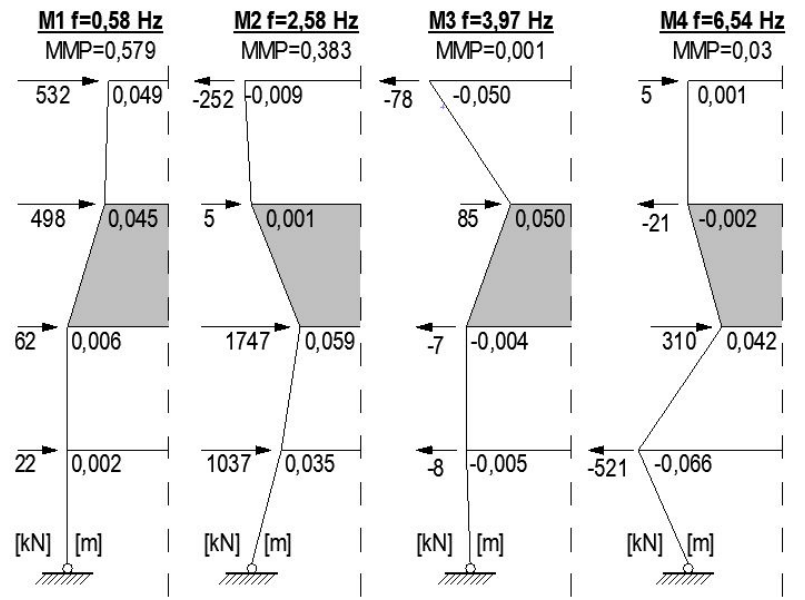

(c)

Fig. 6. Eigenmodes and equivalent horizontal forces of perfect and imperfect 4-storey building
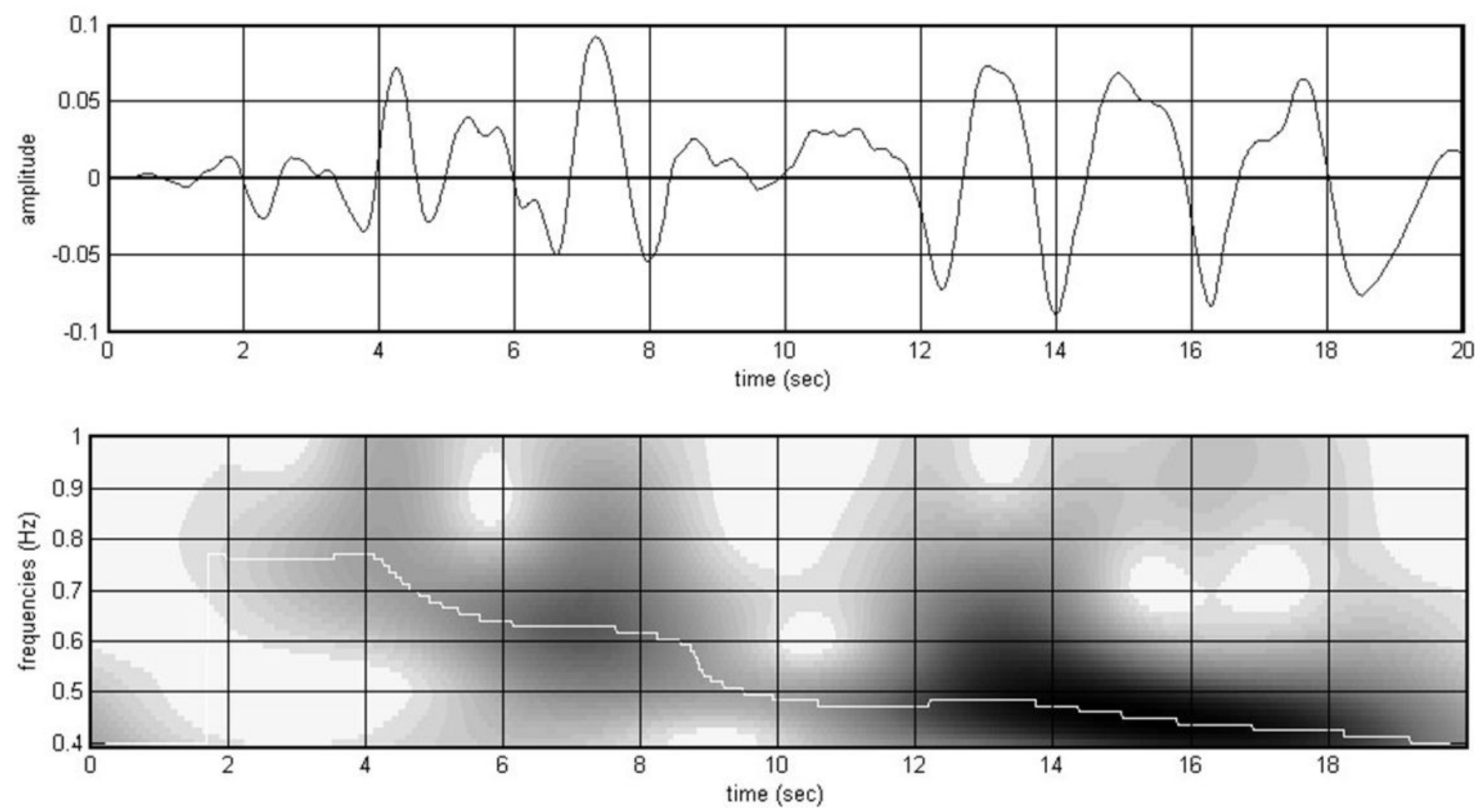

Fig. 7. Displacement and wavelet transform results of the top floor slab 


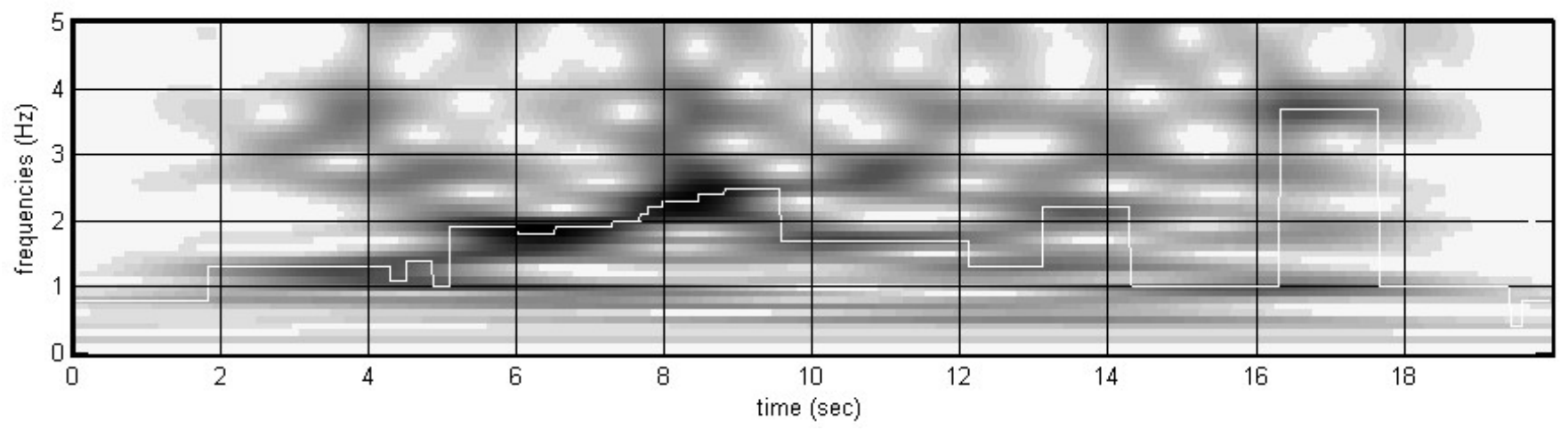

Fig. 8. Wavelet transform of acceleration time series

The parameter $\beta$ defines the length of the envelope wave. By evaluating Eq. (1) on a series of son wavelets in a fixed time and frequency domain we can map the instantaneous frequency components of the analysed signal. The diagram depicting the results is called a scalogram which is analogue with the spectrogram created by Fourier transformation but the time and frequency axes are both variables, therefore the results below are represented by a greyscale colormap. In our case the signal is the horizontal displacement of a selected floor slab coming from an earthquake excitation.

Also the ground accelerogram resulting the horizontal displacement is investigated to see if it excites certain frequencies, see Figure 8 The wavelet transform of the displacements does not show sharp margins in Figure 7, the shape is more cloudlike. This is due to the fact that the excitation and the displacement both miss any kind of harmonic regularity. Furthermore the displacement diagram only has a few waves over the $20 \mathrm{sec}-$ ond time series and this leads to a bad resolution. Nonetheless the local maxima are denoted by a white line on the wavelet transform diagram and this line shows that after the first second of featureless noise the characteristic frequency decreases from about $0,77-0,80 \mathrm{~Hz}$ to $0,45-0,50 \mathrm{~Hz}$ throughout the series. The initial frequency complies with the natural frequency of the perfect structure where the buckled bars in compression are neglected $(0.84 \mathrm{~Hz})$ while the later is equal to the result in Table 2 $(0.50 \mathrm{~Hz})$ corresponding to a model with developed imperfection $(50 \mathrm{~cm})$ on the $4^{\text {th }}$ floor. In the meantime the wavelet transform of the accelerogram does not show any tendentious excitation of distinguished frequencies. These results prove that the gradual change of the natural frequencies and the eigenmodes due to the degradation of diagonals that undergo cumulating plastic deformations throughout the earthquake can be effectively simulated in numerical experiments. Therefore the qualitative change described above in the behaviour of CBFs subjected to seismic action is probable and it has to be taken into consideration in the imposed design criteria.

\section{A proposed design criterion}

On the basis of the behaviour introduced and described above a new design criterion was developed. The method is to be ap- plied complementarily with the prevalent code as the aim was not to create a new design method but to give additional conditions that can prevent the occurrence of local weak storey mechanisms. The basic idea of the Plasticity Analysis for Modal Combinations (PAMC) method is described below. As the modelling and simulation of elastic or plastic behaviour of structures due to different type of dynamic loading is a very complex and difficult task [8 9] the approach was elaborated as a regular plasticity analysis method for the sake of simplicity.

To better understand the way the deterioration of the diagonals affect the modal response of a concentrically braced frame a series of linear modal analyses were run on different imperfectbrace models. The results showed that the modal displacements of the perfect structure and the imperfect ones with concurrent magnitude of imperfection on all storeys are proportional. Consequently the shapes of the equivalent horizontal load patterns of the perfect and the identically imperfect models are closely the same. The essential difference is that the triangular imperfection of the braces results in a significant loss of stiffness so the periods of the modes increase significantly. Consequently the spectral acceleration of the fundamental mode may decrease significantly while the second and other upper modes stay in the interval of the maximum spectral acceleration, see Figure 9 This emphasizes the significance of the upper modes.

Furthermore on the basis of the preceding work of Chopra et al. [3, 4] it is assumed, that only the first mode causes plastic yield in the structure, the higher modes do not. Hence the effect of the higher modes can be calculated using the elastic spectrum. The basic idea of the PAMC method is to apply the horizontal modal forces, calculated with the design spectrum on the perfect structure, and to observe the type of yield mechanism they lead to. CBFs designed with the simplified method of Eurocode 8 withstand horizontal forces corresponding to the shape of the fundamental mode taking into consideration a behaviour factor equal to 4 . In the presented method this initial load pattern is perturbed with horizontal load patterns of the significant upper modes.

In design the structure is expected to stay in the elastic domain for the initial load pattern, hence, for the perturbed patterns, plastic calculations are conducted. The combination of 


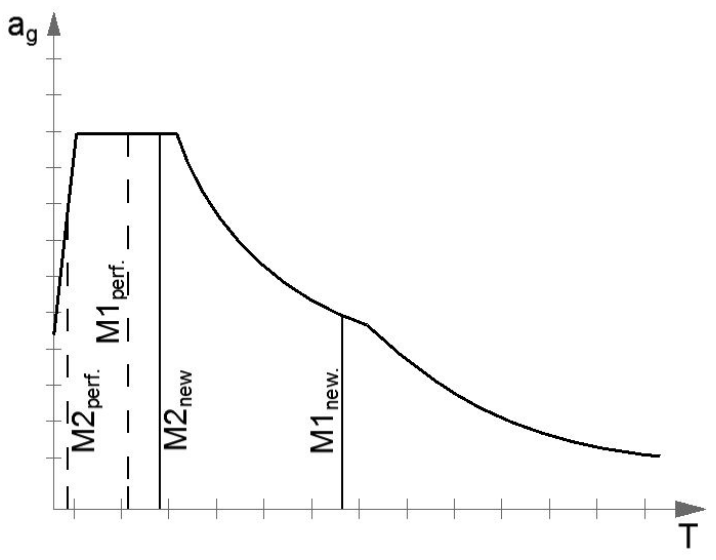

Fig. 9. Change of acceleration response

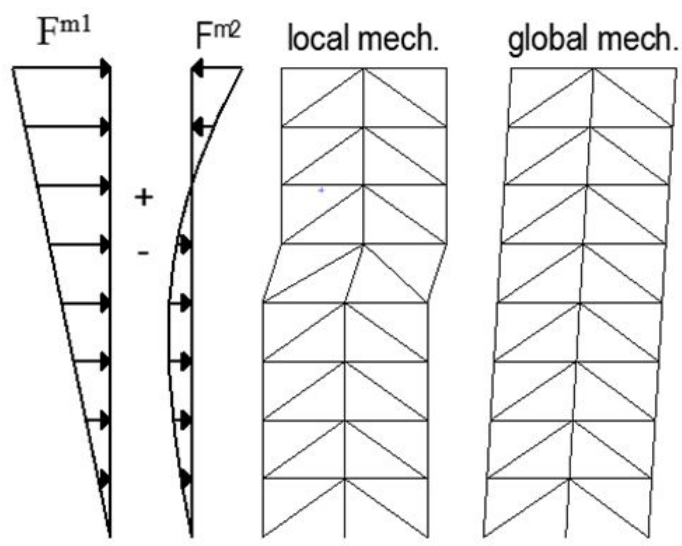

Fig. 10. Concept of the PAMC method

the modal load patterns taken into consideration is:

$$
F_{\text {pamc }}=\frac{F_{M 1}}{q} \pm F_{M 2}\left( \pm F_{M 3 \ldots}\right)
$$

where $F_{\mathrm{M} 1}$ denotes the equivalent horizontal load pattern of the first mode, $\mathrm{q}$ is the behaviour factor. As the equivalent loads alternate with different frequencies they are to be considered with both positive and negative sign in order to obtain the maximum of the storey shear on every floor. The concept of the method is that on each and every floor the plastic load bearing capacity of the storey yield mechanism has to be sufficient to withstand the effect of the load combination above. Therefore the possibility of the development of a weak storey diminishes. The criterion imposed to each storey of the considered building is that the dissipated energy calculated in a weak storey mechanism has to exceed the external work of the described horizontal load pattern, as described by Eq. (5).

$$
W_{\text {ext }}+W_{\text {grav }} \leq W_{\text {int }}
$$

where $W_{\text {ext }}$ is the work of the $F_{\text {pamc }}$ load pattern on the displacements of the local mechanism, $W_{\text {grav }}$ is the work of the gravity forces [2] and $W_{\text {int }}$ is the internal dissipation in the tensile diagonal and the columns on the weak storey as for the development of a local mechanism the columns have to undergo plastic deformations. If the condition (5) is met on every floor of the structure it is expected that it will not collapse with a weak storey mech- anism and by that it is forced to gradually develop the global mechanism.

\section{Conclusions}

In this paper we presented three concentrically braced frames designed according to the prevalent Eurocode standard to withstand a certain seismic action. The designs were numerically tested by a series of ground motions that matched the effect of the design earthquake. The results have shown that the designs are inadequate as the global yield mechanism has not been provided and the buildings were considered to be collapsed at a lower acceleration level than of the design action. Possible reasons to this early storey mechanism failure were presented. Through the plastic behaviour of the diagonals a significant and self amplifying loss of the stiffness and the change of the modal behaviour of the building have been introduced. Furthermore, by the analysis of the displacement time series of the observed buildings subjected to seismic loading we presented numerical evidence to the supposed, cumulating plastic deformationinduced behaviour. A new possible design criterion has been introduced that aims to prevent the development of weak stories throughout the seismic action. As a continuation of this research the new design criterion should be tested. Furthermore new methods can be elaborated that better utilize the findings of this paper.

\section{References}

1 Elghazouli AY, Seismic design procedures for concentrically braced frames, ICE - Structures and Buildings 2003, 2003 november, In: Proceedings of the ICE - Structures and Buildings, Volume 156, Issue 4, ICE, 2003, pp. 381-394, DOI 10.1680/stbu.156.4.381.37840.

2 Tremblay $\mathbf{R}$, Achieving a stable inelastic seismic response for multi-storey concentrically braced steel frames, Engineering Journal, 40(2), (2003), 111129.

3 Kalkan E, Kunnath SK, Assessment of current nonlinear static procedures for seismic evaluation of buildings, Engineering Structures, 29, (2007), 305316, DOI 10.1016/j.engstruct.2006.04.012.

4 Chopra AK, Goel RK, Chintanapakdee C, Evaluation of a modified MPA procedure assuming higher modes as elastic to estimate seismic demands, Earthquake Spectra, 20(3), (2004), 757-778, DOI 10.1193/1.1775237.

5 Longo A, Montuori R, Piluso V, Failure mode control of X-braced frames under seismic actions, Journal of Earthquake Engineering, 12, (2008), 728759, DOI 10.1080/13632460701572955.

6 Elghazouli AY, Seismic design of steel-framed structures to Eurocode 8, 14th WCEE, (Beijing, 12-17 October 2008), In: Proceedings of the fourteenth world conference on earthquake engineering, 2008.

7 Brandonisio G, Toreno M, Grande E, Mele E, De Luca A, Seismic design of concetric braced frames, Journal of Constructional Steel Research, 78, (2012), 22-37, DOI 10.1016/j.jcsr.2012.06.003.

8 Szabó G, Györgyi J, De Luca A, Numerical simulation of the flutter performance of different generic bridge cross section, Periodica Polytechnica Civil Engineering, 55, (2011), 137-146, DOI 10.3311/pp.ci.2011-2.06.

9 Szőke D, Lógó J, Merczel DB, Optimal suspension settings for ride comfort of road vehicles, Periodica Polytechnica - Civil Engineering, 54(2), (2010), 73-78, DOI 10.331/pp.ci.2010-2.01.

10 Kaliszky S, Plasticity: Theory and Engineering Applications, Elsevier Science Publishers, 1989. 
11 Bruneau M, Clifton C, MacRae G, Leon R, Fussell A, Steel Building damage from the Christchurch earthquake of February 22, 2011, NZ, 2011.

12 Nip KH, Gardner L, Elghazouli AY, Cyclic testing and numerical modelling of carbon steel and stainless steel tubular bracing members, Engineering Structures, 32, (2010), 424-441, DOI 10.1016/j.engstruct.2009.10.005.

13 Eurocode 8: Design of structures for earthquake resistance: Part 1: General rules, seismic actions and rules for buildings, CEN, 2005.

14 Büssow R, An algorithm for the continuous Morlet wavelet transform, Mechanical Systems and Signal Processing, 21, (2007), 2970-2979, DOI 10.1016/j.ymssp.2007.06.001.

15 Holschneider $\mathbf{M}$, Kronland-Martinet $\mathbf{M}$, Morlet $\mathbf{J}$, Tchamitchian $\mathbf{P}, A$ real-time algorithm for signal analysis with the help of the wavelet transform, International Conference on Wavelets, (Marseille, France, 14-18 December 1987), In: Combes JM, Grossmann A, Tchamitchian P (eds.), Wavelets, Springer Verlag, 1987.

16 Tremblay R, Archambault M-H, Filiatrault A, Seismic response of concentrically braced steel frames made with rectangular hollow bracing members, Journal of Structural Engineering, 129, (2003), 1626-1636, DOI 10.1061/(ASCE)0733-9445(2003)129:12(1626).

17 Menegott M, Pinto P, Method of analysis for cyclically loaded reinforced concrete plane frames including changes in geometry and nonelastic behaviour of elements under combined normal force and bending, In: IABSE symposium on resistance and ultimate deformability of structures acted on by well-defined repeated loads; Lisbon, Portugal, 1973. Final report. 